\title{
NOTAS INTRODUTÓRIAS PARA UM MÉTODO HISTÓRICO-CRÍTICO DE ALFABETIZAÇÃO
}

\author{
NOTAS INTRODUCTORIAS PARA UN MÉTODO HISTÓRICO-CRÍTICO \\ DE ALFABETIZACIÓN
}

\section{INTRODUCTORY NOTES TO A CRITICAL-HISTORICAL METHOD OF LITERACY}

\author{
Izac Trindade COELHO ${ }^{1}$ \\ Francisco José Carvalho MAZZEU ${ }^{2}$
}

RESUMO: Este artigo aborda a alfabetização na perspectiva da Pedagogia HistóricoCrítica e tem o propósito de indicar fundamentos teóricos que contribuam para elaborações metodológicas coerentes com os pressupostos dessa concepção pedagógica. Buscando referências em diferentes áreas do conhecimento procuramos apontar alguns dos elementos que poderiam fundamentar um método histórico-crítico de alfabetização, dentre eles: a necessidade de superar dialeticamente os métodos já existentes, a identificação dos conteúdos e objetivos do processo de alfabetização, a centralidade da palavra como instrumento-guia no processo de ensino-aprendizagem e a necessidade de resgatar o papel do professor como produtor das suas próprias atividades didáticas. Espera-se com esse trabalho fomentar um debate frutífero que resulte em avanços na direção de oferecer aos professores que alfabetizam um conjunto de orientações mais específicas sobre como podem inserir o seu trabalho no âmbito da Pedagogia HistóricoCrítica.

PALAVRAS-CHAVE: Alfabetização. Pedagogia histórico-crítica. Métodos de alfabetização.

RESUMEN: Este artículo aborda la alfabetización en la perspectiva de la Pedagogía Histórico-Crítica y tiene el objetivo de indicar fundamentos teóricos que contribuyan para elaboraciones metodológicas coherentes con los aportes de esa concepción pedagógica. A partir de la busca de referencias en diferentes áreas del conocimiento intentamos apuntar algunos de los elementos que podrían fundamentar un método histórico-crítico de alfabetización, entre ellos: la necesidad de superar dialécticamente los métodos ya existentes, la identificación de los contenidos y objetivos del proceso de alfabetización, la centralidad de la palabra como instrumento-guía en el proceso de enseñanza-aprendizaje y la necesidad de rescatar el papel del profesor como produtor de sus propias actividades didácticas. Se espera con ese trabajo fomentar un debate fructífero que resulte en avances en la dirección de ofrecer a los profesores que alfabetizan un conjunto de orientaciones más específicas sobre cómo pueden inserir su trabajo en el ámbito de la Pedagogía Histórico-Crítica.

1 Mestre em Educação Escolar. Departamento de Educação - Faculdade de Ciências e Letras, FCLAr/UNESP. Programa de pós-graduação em Educação Escolar, Araraquara, Brasil. E-mail: izac.tcoelho@gmail.com

${ }^{2}$ Doutor em Educação. Departamento de Didática. Faculdade de Ciências e Letras - FCLAr/UNESP, Araraquara, Brasil. E-mail: fmazzeu@gmail.com. 
PALABRAS CLAVE: Alfabetización. Pedagogía histórico-crítica. Métodos de alfabetización.

ABSTRACT: This article deals with literacy according to Critical-Historical Pedagogy, aiming at establishing theoretical foundations which can contribute to the development of methodological tools coherent with the assumptions of such pedagogy. Adopting several theoretical approaches, assumptions that may accurately substantiate a critical-historical method of literacy are underlined, such as: the need of a dialectically overcome of the current literacy methods; the identification of literacy's contents and objectives; the centrality of word as a guiding-tool in such teaching/learning process; and the need of redeeming teacher's role as a producer of his own teaching activities. This article looks forward to a lively and fruitful debate resulting faster and more consistent advances in providing literacy teachers with a more specific guidance on how to carry out their own work inside the scope of the Critical-Historical Pedagogy.

KEYWORDS: Literacy. Critical-historical pedagogy. Literacy methods.

\section{Introdução: a Pedagogia Histórico-Crítica e os métodos tradicionais de Alfabetização}

Para situar a abordagem da Pedagogia Histórico-Crítica (PHC) no âmbito da alfabetização é necessário inicialmente pontuar alguns aspectos gerais dessa teoria. A PHC vê a escola, no contexto da luta de classes, como um espaço de disputa hegemônica e faz a defesa intransigente de uma escola pública unitária, com qualidade para todos, rica em conteúdos vivos e relevantes, que transmita o conhecimento humano historicamente acumulado em suas formas mais desenvolvidas, a fim de contribuir para a formação de seres humanos capazes de transformar a realidade social.

O desenvolvimento da PHC tem avançado com mais força na formulação dos fundamentos teóricos, fazendo crescer a demanda para que essa concepção "exerça maior influxo sobre a prática" (SAVIANI, 2007). No campo da alfabetização, à medida que avançam as críticas à concepção hegemônica do construtivismo, a partir de pressupostos histórico-culturais (MARTINS; MARSIGLIA, 2015), torna-se mais evidente a necessidade de explicitar as implicações metodológicas dessa abordagem teórica, a fim de oferecer orientações e indicações práticas para o trabalho do professor em sala de aula.

A chamada "querela dos métodos" (MORTATTI, 2000) que periodicamente vem à tona nesse campo, ilustra a dificuldade de superar os limites e as armadilhas do pensamento dominante, sustentado pelo formalismo lógico. A relativa hegemonia conquistada pelo construtivismo no debate acadêmico e nas políticas públicas de 
alfabetização nos últimos 30 anos pode levar os pesquisadores que se contrapõem a essa hegemonia a caírem na tentação de apoiarem o "movimento pendular" que defende a restauração de métodos tradicionais, como o Método Fônico (CAPOVILLA, A.; CAPOVILLA, F., 2002), ou até mesmo a vislumbrar nas antigas cartilhas um caminho possível para assegurar que a escola cumpra sua finalidade de garantir o domínio da linguagem escrita para todos os alunos.

Ainda que a luta hegemônica contra o construtivismo e suas concepções antipedagógicas (DUARTE, 2001) pudesse se valer de algum grau de "curvatura da vara" (SAVIANI, 2007) na direção dos métodos tradicionais, vale lembrar que o desafio fundamental é superar essa "fase romântica" marcada pela polêmica e ingressar na "fase clássica" (GRAMSCI, 1982, p.124):

\begin{abstract}
Ainda se está na fase romântica da escola ativa, na qual os elementos da luta contra a escola mecânica e jesuítica se dilataram morbidamente por causa do contraste e da polêmica: é necessário entrar na fase "clássica", racional, encontrando nos fins a atingir a fonte natural para elaborar os métodos e as formas. (GRAMSCI, 1982, p.124).
\end{abstract}

Esse seria, portanto, o primeiro desafio da elaboração de um método históricocrítico de alfabetização: superar dialeticamente os principais métodos já existentes, identificando o seu núcleo válido, desarticulando esses elementos válidos do quadro teórico limitado em que estão inseridos e os rearticulando em uma nova base conceitual que permita seu pleno desenvolvimento. A título de indicação dos contornos dessa tarefa, podemos indicar alguns dos traços essenciais que caracterizam os métodos tradicionais e as cartilhas e que explicam porque esse tipo de abordagem "funciona" na prática de sala de aula. Um desses aspectos se refere ao ensino sistemático das relações entre fonemas e letras que, como explica Magda Soares, caracteriza a própria especificidade do processo de alfabetização (SOARES, 2004). Um traço comum aos métodos tradicionais de alfabetização é a organização do ensino por meio de uma sequência definida de passos ou etapas a serem vencidas pelo aluno para dominar as relações entre fonemas e letras, adquirindo a capacidade de ler e escrever com autonomia.

Essa característica de progressividade se mostra de modo evidente nas Cartilhas, organizadas por meio de "lições" sucessivas. Vencer uma lição, aprendendo o conteúdo nela previsto, é a condição para seguir para a próxima. Dessa forma, esses métodos e materiais didáticos criam uma sequência ideal a ser seguida por todos os alunos. 
Consequentemente, criam também um processo de avaliação processual, pois um aluno que não conseguiu aprender determinada lição precisará receber uma atenção especial para que possa retomar o caminho previsto inicialmente. Essa forma de organizar o processo de alfabetização também se reflete na necessidade de um planejamento por parte do professor para estabelecer a sequência mais adequada de conteúdos e de exercícios a serem realizados pelos alunos em cada lição.

Os aspectos citados (planejamento, progressão, avaliação constante) fazem parte do caráter sistemático do ensino das relações entre fonemas e letras e não se confundem com o mecanicismo que é alvo de críticas por parte de vários pesquisadores. Saviani (2013, p.18) aponta que,

Com efeito, a crítica ao ensino tradicional era justa, na medida em que esse ensino perdeu de vista os fins, tornando mecânicos e vazios de sentido os conteúdos que transmitia. A partir daí, a Escola Nova tendeu a considerar toda transmissão de conteúdo como mecânica e todo mecanismo como anticriativo, assim como todo automatismo como negação da liberdade.

O autor considera a aquisição de automatismos como condição para uma atividade autônoma e livre, e utiliza como exemplo exatamente a alfabetização para explicar que existe uma relação dinâmica entre os processos ditos mecânicos e o uso significativo e criativo da linguagem escrita.

Ora, esse fenômeno está presente também no processo de aprendizagem através do qual se dá a assimilação do saber sistematizado, como o ilustra, de modo eloquente, o exemplo da alfabetização. Também aqui é necessário dominar os mecanismos da linguagem escrita. Também aqui é preciso fixar certos mecanismos, incorporá-los, isto é, torná-los parte de nosso corpo, de nosso organismo, integrá-los em nosso próprio ser. Dominadas as formas básicas, a leitura e a escrita podem fluir com segurança e desenvoltura. À medida que se vai libertando dos aspectos mecânicos, o alfabetizando pode, progressivamente, ir concentrando cada vez mais sua atenção no conteúdo, isto é, no significado daquilo que é lido ou escrito. Note-se que se libertar, aqui, não tem o sentido de se livrar, quer dizer, abandonar, deixar de lado os ditos aspectos mecânicos. A libertação só se dá porque tais aspectos foram apropriados, dominados e internalizados, passando, em consequência, a operar no interior de nossa própria estrutura orgânica. Poder-se-ia dizer que o que ocorre, neste caso, é uma superação no sentido dialético da palavra. Os aspectos mecânicos foram negados por incorporação e não por exclusão. Foram superados porque negados enquanto elementos externos e afirmados como elementos internos. (SAVIANI, 2013, p.18, grifo nosso). 
No entanto, não se pode compreender essa dinâmica de um modo formal. Como o autor explica no trecho por nós destacado, a atenção ao conteúdo do que é lido ou escrito vai se tornando cada vez mais o elemento central, à medida que o uso automático dos processos de codificação e decodificação se consolida. Isso quer dizer que o aspecto semântico não está ausente no início do processo, mas se torna um elemento secundário e determinado na relação com os aspectos grafofonêmicos, quando estes são o foco principal da atenção do aluno. Ao longo do processo de alfabetização essa relação se inverte (ou pelo menos assim deveria ocorrer). No entanto, se não houver a presença do significado (e sentido) daquilo que é lido ou escrito, desde o início, esse processo pode não levar a uma superação dialética, mas a uma negação formal, ou seja, pode induzir ao uso esvaziado da linguagem escrita, no qual o conteúdo permanece em segundo plano e é tratado de forma superficial mesmo com a formação dos automatismos necessários para ler e escrever.

Ainda assim, é preciso deixar claro e expressar com a devida ênfase, que, do ponto de vista histórico, social e político é melhor que ocorra uma alfabetização marcada pelo mecanicismo, que poderá ser futuramente superada pelo esforço do aluno, do que uma pseudo-alfabetização em que a participação ativa do aluno sacrifique o domínio dos conteúdos necessários para o uso efetivo da escrita, o que impede qualquer superação posterior. Portanto, a adoção de uma abordagem histórico-crítica implica em uma rejeição categórica do construtivismo enquanto teoria e método de alfabetização. No entanto, duas questões se colocam como decorrência dessa afirmação: existe realmente um método construtivista a ser superado? Se existe, não teria ele também um núcleo válido a ser incorporado em uma abordagem histórico-crítica?

Em relação à primeira questão, a resposta pode ser sim ou não, dependendo do conceito de método que se está adotando.

\section{O conceito de método na PHC e a abordagem construtivista}

$\mathrm{Na}$ sua estratégia de se contrapor aos métodos tradicionais de alfabetização, o construtivismo reduziu o conceito de método a um conjunto de passos a serem seguidos rigidamente pelo alfabetizador, o que levaria a interdições e práticas rituais por parte dos professores. Com base nessa visão restrita do que é um método, Ferreiro (1995, p.22) afirma que: 
[...] tradicionalmente, as discussões sobre a prática alfabetizadora têm se centrado na polêmica sobre os métodos utilizados: métodos analíticos versus métodos sintéticos; fonético versus global, etc. Nenhuma dessas discussões levou em conta o que agora conhecemos: as concepções das crianças sobre o sistema de escrita. Daí a necessidade imperiosa de recolocar a discussão sobre novas bases. Se aceitarmos que a criança não é uma tábua rasa onde se inscrevem as letras e as palavras segundo determinado método; se aceitarmos que o "fácil" e o "difícil" não podem ser definidos a partir da perspectiva do adulto, mas da de quem aprende; se aceitarmos que qualquer informação deve ser assimilada (e portanto transformada) para ser operante, então deveríamos também aceitar que os métodos (como sequência de passos ordenados para chegar a um fim) não oferecem mais do que sugestões, incitações, quando não práticas rituais ou conjunto de proibições. O método não pode criar conhecimento.

No entanto, dentro de uma abordagem materialista-dialética, o método é indissociável de uma ação humana intencional. Como afirma Vieira Pinto (1979, p.373), "[...] intencionalidade e método são uma só coisa, conforme se documenta inclusive pela analogia etimológica, pois os dois termos na composição vernacular querem dizer a mesma coisa, apenas um na acepção latina e o outro na grega". Portanto, o método é uma forma de agir que se diferencia do agir espontâneo, pois implica em uma ação dirigida consciente e voluntariamente por determinado objetivo.

Nesse sentido, é possível afirmar que o construtivismo também propõe um método de alfabetização, pois define objetivos para o ensino e traça estratégias a serem seguidas pelo professor para alcançá-los. Por isso, somos levados a discordar da afirmação de Soares (2004, p.2), de que "[...] se antigamente havia método sem teoria, hoje temos uma teoria sem método". Apenas a título de indicação, alguns dos passos ou momentos principais do método construtivista consistem em:

- aplicar a sondagem a todos os alunos e classificá-los em determinada etapa ou hipótese (pré-silábica, silábica, silábico-alfabética, alfabética);

- $\quad$ apresentar ao aluno as letras do alfabeto todas de uma vez no começo das aulas, por meio de cartazes e do material chamado "alfabeto móvel";

- $\quad$ propor atividades com listas de palavras de um mesmo campo semântico, especialmente os nomes dos alunos, para que eles tentem escrever "do jeito que souberem" utilizando as letras do alfabeto já apresentadas;

- colocar os alunos em "agrupamentos produtivos" combinando aqueles que se encontram em fases ou hipóteses diferentes, porém próximas, para que a 
interação entre eles leve à mudança de hipóteses;

- fazer intervenções e aplicar atividades didáticas específicas para cada fase, a fim de desequilibrar as hipóteses dos alunos e provocar o surgimento de novas hipóteses até a "descoberta” da hipótese alfabética.

É evidente que essa sequência é uma simplificação, mas não foge muito do modelo que vem sendo adotado por muitos professores considerados construtivistas e das orientações definidas, por exemplo, para o ensino público estadual em São Paulo (SÃO PAULO, 2010). O construtivismo, como qualquer proposta que pretende ser hegemônica, foi também incorporando aspectos de outras abordagens como os estudos sobre as práticas de letramento, por meio do uso de textos de diferentes gêneros para atividades de leitura e escrita (embora reduzindo o conceito de gênero ao tipo formal de texto e limitando os gêneros àqueles próximos ao cotidiano dos alunos, conforme aponta Meyer (2016)). Até mesmo a forma de trabalho em pequenos grupos de alunos é indevidamente atribuída a uma incorporação das ideias de Vygotsky, que defenderia a "interação social" no ensino (para uma crítica a esse tipo equivocado de apropriação, vide Duarte (2001)).

$\mathrm{O}$ objetivo central que dirige o método construtivista está em fazer com que o aluno "recrie" ou "redescubra" o sistema alfabético de escrita, por meio de atividades em que confronta suas hipóteses iniciais com dados fornecidos pelos colegas, pelos materiais escritos presentes no ambiente, pelo professor ou por outros informantes, refletindo sobre a escrita das palavras até compreender a lógica geral do sistema. Com isso estaria assimilando o sistema alfabético de escrita de modo significativo e desenvolvendo sua autonomia intelectual e moral.

Não é muito fácil encontrar aspectos válidos nessa abordagem, uma vez que ela conduz a uma situação em que o ensino fica a reboque dos processos de aprendizagem e, portanto, não busca assegurar que todos atinjam determinado resultado, mas sim que “avancem nas suas hipóteses". A ideia de que o aluno que escreve de forma alfabética já estaria alfabetizado, mesmo sem domínio das regras ortográficas, também conduz a graves problemas para a escola e para os alunos. No entanto, podemos apontar que o construtivismo trouxe uma contribuição importante ao chamar a atenção para processos de aprendizagem que passavam despercebidos aos olhos dos professores, evidenciando que a alfabetização envolve aspectos amplos que não se limitam ao treino motor, discriminação auditiva e visual e associação entre fonemas e letras. Talvez o principal aspecto válido a ser considerado seja a atitude do professor que alfabetiza em relação 
aos alunos. Os métodos tradicionais e as cartilhas se tornaram, ao longo do tempo, muito formais e distantes do uso efetivo da escrita na prática social e deram sustentação a uma atitude de desqualificação, quando não de repressão e desrespeito, às tentativas do aluno para ler e escrever que fujam do padrão estabelecido e esperado (e mesmo das variantes orais que fogem a uma pretensa "norma culta"). Dessa forma, o construtivismo trouxe uma atitude mais compreensiva em relação aos erros que o aluno comete e que são inerentes ao processo de aprendizagem. Infelizmente esse aspecto válido foi contaminado pela concepção geral do construtivismo, que passa a considerar todo erro como sendo construtivo e positivo, o que na prática elimina a própria noção de erro.

Portanto, atividades em que os alunos possam discutir coletivamente como se faz para escrever uma palavra ou mesmo apresentar com tranquilidade suas tentativas iniciais e suas dúvidas precisam fazer parte do trabalho do alfabetizador, que deve estar atento para a natureza das dificuldades dos alunos a fim de promover o seu máximo desenvolvimento possível na direção dos objetivos pedagógicos da alfabetização. Entender o momento em que o aluno se encontra no processo de aquisição da escrita é fundamental, mas não precisa (nem deveria) resultar em uma didática específica para cada fase desse processo. Por exemplo, em uma sala com alunos considerados présilábicos, silábicos, etc. (os limites e fragilidades dessa classificação estão sendo objeto de outra pesquisa em andamento a ser futuramente divulgada), enquanto os métodos tradicionais ignoram essas diferenças, o construtivismo sugere que o professor elabore um tipo de atividade para cada grupo, o que pode acabar reforçando as diferenças. Sugerimos, ao contrário, que o professor procure fazer uma explicação ou dar uma atividade comum a todos, mas observe atentamente quais os alunos que necessitam de um auxílio maior e qual o tipo de apoio que melhor funciona em cada caso. A grande questão está em encontrar os meios mais adequados para conduzir o aluno a realizar a atividade de forma correta, sem que isso aconteça apenas através da cópia das respostas certas. É nesse ponto que o conceito de zona de desenvolvimento próximo (ou imediato) proposto por Vygotsky (1995) se torna essencial, pois revela aquelas capacidades e funções que ainda não estão amadurecidas, mas que já existem em estado embrionário e possibilita identificar quais as atividades de ensino, exercícios e tarefas que desencadeiam e fortalecem essas capacidades e funções nascentes.

Como explica Saviani (2007), o processo educativo pressupõe uma desigualdade no ponto de partida e uma igualdade no ponto de chegada. Portanto, são os objetivos da 
alfabetização (ponto de chegada) que precisam determinar a escolha das atividades de ensino que cada aluno irá executar a partir de suas capacidades já desenvolvidas (ponto de partida), capacidades essas a serem superadas por meio de atividades e instrumentos mediadores produzidos e utilizados pelo professor.

\section{Sobre os objetivos da alfabetização na PHC}

Dizer que o objetivo da alfabetização é ensinar os alunos a ler e escrever ou que o objetivo seja assegurar o domínio da linguagem escrita, apesar da aparente obviedade, revela um aspecto importante, pois situa esse objetivo no âmbito de uma capacidade a ser desenvolvida nos alunos e aponta para o conteúdo central envolvido nessa capacidade. Entender o que significa ler e escrever e o que é a linguagem escrita são, portanto, aspectos essenciais para fundamentar um método de alfabetização. Não há no presente texto a pretensão sequer de esboçar uma concepção sobre esses dois aspectos, apenas indicar a necessidade de uma abordagem histórico-crítica desses pontos e levantar alguns elementos que podem contribuir para essa tarefa.

Em relação à leitura, existe uma histórica disputa entre duas visões sobre o que é um leitor proficiente e, portanto, sobre como formá-lo (SOARES, 2004): de um lado os partidários da chamada leitura significativa (whole language) e de outro os que defendem a leitura de base fonológica (phonics). Além da necessidade evidente de uma abordagem Histórico-Crítica superar esse formalismo e considerar esses dois processos como momentos dialeticamente integrados (MAZZEU, 2012), coloca-se o desafio de ir além e perceber que ambas as abordagem limitam a leitura a uma recuperação do significado do texto.

A partir dos estudos da Psicologia Histórico-Cultural entendemos que a formação de um leitor implica na capacidade de perceber também o sentido do que está escrito (seja um texto ou uma palavra). Luria (1986) chamou de subtexto esse sentido subjacente que não se evidencia à primeira vista, mas é essencial para compreender o que está escrito. Tratando da questão de como analisar a legislação, Saviani (1996, p.146) explica que "[...] para compreender o real significado da legislação não basta ater-se à letra da Lei; é preciso captar o seu espírito. Não é suficiente analisar o texto; é preciso analisar o contexto. Não basta ler nas linhas; é preciso ler nas entrelinhas”.

Podemos perceber nessa ideia uma concepção do que é a formação de um leitor 
crítico, que seria um dos objetivos principais de um método Histórico-Crítico de alfabetização. Naturalmente a formação desse leitor não se completa na alfabetização, mas nela precisa se iniciar. Analogamente, a formação de autores de textos que expressem um sentido autêntico e não apenas reproduzam palavras vazias precisa estar no horizonte para orientar o trabalho do alfabetizador. Essas ideias apontam para outra questão: como o ensino dos conteúdos específicos da alfabetização (a relação entre fonemas e letras) contribui para a formação desse tipo de leitor e autor de textos?

\section{Concepção de linguagem escrita e os conteúdos da alfabetização na PHC}

Considerando que a linguagem escrita é o conteúdo central da alfabetização, ainda que o desenvolvimento da oralidade também constitua parte das tarefas do professor, a definição dos conteúdos específicos a serem ensinados na alfabetização implica em adotar uma determinada concepção sobre o que é a escrita. Em breves linhas, podemos apontar que existem duas visões principais, que Ferreiro (1995) simplifica como: a escrita como um código de transcrição da fala (que ela critica) e a escrita como um sistema de representação (que ela adota). Sem entrar no mérito dessas abordagens ou de outras que procuram complementar a visão construtivista (por exemplo: Soares (2016) considera a escrita como "sistema notacional"), encontramos em Luria (2001) a concepção da escrita como uma técnica histórico-social. Essa definição também aparece em outros textos de Soares (2004), mas não é desenvolvida do ponto de vista histórico-cultural, nem dela se extraem suas devidas consequências pedagógicas.

Para Saviani (2007, p.63) "[...] a técnica pode ser definida, de modo simples, como a maneira julgada correta de se executar uma tarefa". Dominar a escrita requer o uso das formas que a sociedade considera corretas para ler e escrever. Portanto, os conteúdos da alfabetização incluem o estudo das letras e suas relações com os fonemas não apenas do ponto de vista da construção de um sistema alfabético pela criança, mas do domínio das relações ortográficas construídas histórica e socialmente. Ocorre que não é o conhecimento dessas relações por si mesmo que precisa ser assegurado, mas o seu uso adequado por meio das técnicas usadas socialmente para ler e para escrever. Nesse contexto é que se coloca a necessidade de seleção dos conteúdos da alfabetização, que precisam possibilitar o domínio das técnicas de leitura e produção de palavras, frases e textos, englobando desde as técnicas mais elementares de codificação e 
decodificação até aquelas que permitem a identificação do significado e sentido de palavras e textos, bem como a expressão do pensamento por meio da linguagem escrita. No entanto, são as técnicas elementares, que permitem ler e escrever palavras, frases e textos mais simples, que irão constituir o conteúdo principal da alfabetização. Sendo assim, ao contrário da visão tradicional, que coloca as relações grafofonêmicas e as regras ortográficas como conteúdo central e do construtivismo, que foca na compreensão geral do sistema alfabético de escrita, o que se sugere aqui é um ensino centrado no uso da escrita como instrumento de formação de leitores/autores críticos, a partir da prática histórica e socialmente desenvolvida.

Seriam esses objetivos e conteúdos, aqui indicados de forma extremamente sucinta e preliminar, que poderiam orientar a elaboração de algumas perspectivas metodológicas.

\section{Algumas indicações metodológicas}

Apoiado em Marx, Saviani (2007, p.83) afirma que "[...] o movimento que vai da síncrese à síntese, por mediação da análise, constitui um caminho seguro tanto para a pesquisa científica quanto para o processo de ensino-aprendizagem”, e, sob essa concepção metodológica, estabelece cinco momentos de um método pedagógico Histórico-Crítico: “1) a prática social (ponto de partida); 2) a problematização; 3) a instrumentalização; 4) a catarse, e 5) a prática social (ponto de chegada)". (SAVIANI, 2007, p.80).

Traduzir esses "passos" para a metodologia da alfabetização não é uma tarefa simples que se resolva apenas inserindo os conteúdos dessa área na sequência sugerida, mas requer uma compreensão do sentido geral da proposta apresentada por Saviani (2007) que insere o trabalho do professor e da escola como uma atividade mediadora no contexto de uma prática social determinada pelas relações contraditórias de uma sociedade de classes. Por isso uma ação metódica do alfabetizador implica em uma compreensão da função mediadora do trabalho de alfabetizar, isto é, implica em entender que esse trabalho realiza uma verdadeira transformação na prática social dos alunos e, em decorrência, influencia a sociedade como um todo. Isso ocorre porque a alfabetização conduz cada aluno a avançar de uma prática social de comunicação baseada apenas na oralidade para uma comunicação baseada também na escrita; de um 
uso espontâneo da linguagem oral para um uso mais intencional dela; de uma atividade psíquica predominantemente direta, suportada pelas estruturas biológicas naturais do cérebro, para uma atividade cada vez mais mediada por signos e apoiada nas neoformações cerebrais, que encontram no uso da escrita um poderoso motor de desenvolvimento.

Considerando esse caráter transformador do trabalho de alfabetizar, indicamos sucintamente algumas orientações que poderiam ajudar a direcionar esse trabalho no sentido de maior aproximação com os pressupostos da PHC. Lembramos também que orientações metodológicas não constituem por si mesmas um "método". Como lembra Vieira Pinto (1979, p.375), “[...] não devemos identificar o caminho ao mapa do caminho". Um método histórico-crítico só pode ser produzido pelo professor alfabetizador no seu trabalho, ao agir de modo intencional, com apoio destas e de outras orientações, bem como de uma sólida fundamentação teórica.

No nosso entender o elemento central em torno do qual deveria se organizar a alfabetização seria um conjunto de palavras-mediadoras. As razões que fundamentam essa ideia encontram-se detalhadas na dissertação de mestrado "Pedagogia HistóricoCrítica e Alfabetização: elementos para uma perspectiva histórico-crítica do ensino da leitura e da escrita" (COELHO, 2016). Outros autores que abordam a alfabetização na perspectiva histórico-cultural (MARTINS; DANGIÓ, 2015) também indicaram a centralidade da palavra no ensino da escrita:

A nosso juízo, o domínio da palavra representa a célula nuclear do ensino da linguagem escrita, uma vez que ela, conforme já indicado, unifica duas funções psíquicas de especial grandeza: linguagem e pensamento. (MARTINS; DANGIÓ, 2015, p.216).

A palavra possibilita trabalhar sistematicamente com as relações grafofonêmicas, sem perder de vista o significado e o sentido inerentes à linguagem. Os estudos acerca do pensamento e da linguagem de Vygotsky (1995) e Luria $(1979,2001)$ nos permitem afirmar que o trabalho com a dimensão semântica da palavra é condição necessária para uma alfabetização histórico-crítica. A palavra sem significado, dirá Vygotsky (1995), é um som oco. E é a multiplicidade de sentidos que a palavra pode adquirir numa comunicação verbal ou em um texto que poderá desenvolver a dimensão crítica da leitura e da escrita. Uma palavra possui sentidos variados para diferentes sujeitos, o que expressa relações determinadas socialmente (BAKHTIN; VOLOCHINOV, 1986). Ao dizer a palavra "casa", por exemplo, o aluno tem consciência de que essa palavra se 
refere a um local específico, mas a depender de fatores histórico-sociais, da classe social, da qualidade da educação anterior, esta palavra muda seu significado e seu sentido. Esse significado também vai se modificando à medida que o aluno desenvolve o pensamento abstrato-conceitual e sua compreensão da realidade.

Para mostrar o significado da palavra é necessário, portanto, contextualizá-la. Propomos que isso seja feito por meio de um texto, escolhido exatamente por ter essa palavra como elemento central. A seleção desses textos deveria considerar o conteúdo, que procuraria trazer aspectos relevantes da prática social, mas também a forma que deveria conter palavras e frases adequadas para que sejam trabalhados os conteúdos principais da alfabetização. Na escolha dos textos há que considerar também aqueles que se tornaram clássicos na literatura destinada ao tipo de aluno que está sendo alfabetizado (MARTINS; MARSIGLIA, 2015).

No entanto, o foco no significado e sentido da palavra constitui apenas o momento inicial, sincrético, do estudo das técnicas de leitura e escrita. A palavra-mediadora, como um instrumento pedagógico, constitui um meio para facilitar a apresentação dos conteúdos da alfabetização de forma dosada e sequenciada. Sendo assim, cada palavramediadora, além de estimular o processo de formação de conceitos mais abstratos sobre a realidade, possibilita apresentar um conjunto definido de técnicas de leitura e escrita e de regras do sistema alfabético-ortográfico. Por exemplo, a palavra "casa" coloca em evidência o uso da letra "c" com o som /k/, da letra "s" com o som /z/, do papel desempenhado pela posição dessa letra (início, meio ou final da palavra) na definição do fonema que irá representar, entre outros aspectos.

Na seleção de palavras não há motivos para se restringir àquelas que pertencem ao universo vocabular dos alunos, ao contrário, trata-se exatamente de enriquecer esse vocabulário e aprofundar a compreensão dos conceitos expressos por palavras que os alunos já dominam. O contato do aluno com uma palavra que ainda não lê nem escreve, mas necessita ler e escrever, constitui um momento de problematização do uso da linguagem escrita. No entanto o objetivo central do uso da palavra é possibilitar o uso instrumental do sistema alfabético-ortográfico como meio de comunicação. Isso requer a tomada de consciência da estrutura fonética da palavra falada, o seu desmembramento em unidades menores e sua reprodução voluntária em signos escritos (VYGOTSKY, 1995).

Nesse trabalho de decomposição consciente e voluntária da palavra falada pelo menos duas dimensões precisam ser consideradas: a silábica e a fonológica. Ao 
contrário do construtivismo que acabou por praticamente descartar o trabalho com as sílabas, consideramos que a silabação é fundamental para a apropriação da linguagem escrita (MENDONÇA, O. S.; MENDONÇA, O. C., 2009). O salto qualitativo vivido pelo aluno quando internaliza o processo de segmentação das palavras em sílabas é decisivo para o estabelecimento de uma relação diferenciada com a escrita e com a oralidade. Assim também ocorre com a consciência dos fonemas, ou seja, com a percepção de que cada letra possui um valor sonoro específico que é distintivo do significado das palavras. É por meio da percepção de diferenças entre palavras como "faca" e "vaca" que vai ocorrendo a tomada de consciência dos fonemas e suas complexas relações com os grafemas no sistema de escrita alfabético-ortográfico. É o uso efetivo dos conceitos e regras do sistema alfabético-ortográfico (e não a mera "reflexão" sobre o sistema) que vai instrumentalizando o aluno para passar para as fases mais avançadas de compreensão desse sistema, até que esse uso se torne um automatismo.

No entanto, a passagem da utilização prática das relações entre grafemas e fonemas em atividades conduzidas pelo professor e apoiada por colegas (portanto, intersubjetivas) para um automatismo intrasubjetivo (ou seja, a catarse) não se dá espontaneamente ou com pouco esforço. O aluno precisa realizar um longo processo que envolve exercícios repetidos, intencionalmente organizados pelo professor, para que progressivamente vá assimilando essa nova forma de atividade e vá incorporando-a à sua natureza biológica.

Vygotsky (1995) alerta que as principais dificuldades do aluno nesse processo não são de natureza sensório-motora (embora estas possam existir), mas decorem da mudança profunda para um tipo de atividade mais consciente e voluntária, que exige o uso de funções superiores de atenção, percepção, memória e pensamento abstrato que estão apenas embrionárias no aluno, mas que a atividade de uso da escrita terá o papel decisivo de desenvolver e consolidar.

\section{Considerações finais}

O intuito de contribuir com o avanço da teoria pedagógica Histórico-Crítica foi o que nos motivou a esboçar aqui algumas ideias sobre a elaboração de um método de alfabetização que seja articulado a essa concepção pedagógica, sabendo de antemão que 
tais apontamentos são apenas provocações iniciais e preliminares para instigar outros pesquisadores a avançar nessa tarefa.

Do ponto de vista do ensino da leitura e da escrita, sugerimos que a palavra, como uma unidade fonética e semântica, apresenta-se como elemento central na organização do trabalho do alfabetizador, já que partindo dessa unidade, percebida pelo aluno inicialmente de forma sincrética e depois sendo objeto de análises e sínteses, estaremos ensinando a linguagem escrita como uma técnica social que permite compreender o pensamento registrado por outros e registrar o próprio pensamento. O domínio das relações entre as letras e os sons de uma língua, entre os grafemas e fonemas, é o conteúdo básico a ser dominado por meio do aprendizado dessas técnicas de ler e escrever. Sem o domínio das técnicas de codificação e decodificação não há leitura e não há escrita, mas o ler e escrever não podem ser reduzidos ao uso dessas técnicas elementares, já que é a capacidade de recuperar e expressar significados e sentidos que permite aos alunos ingressarem de fato no mundo da cultura letrada.

O método, enquanto ação intencional, implica na produção, pelo professor, de atividades didáticas decorrentes dos objetivos do seu trabalho pedagógico na alfabetização, tanto aqueles que estão intrinsecamente vinculados com a apropriação do sistema de escrita alfabético-ortográfico quanto aqueles ligados às práticas de letramento e à leitura e produção de textos. A palavra atua como um mediador fundamental entre essas duas dimensões.

Em decorrência do trabalho sistemático tanto do professor quanto dos alunos em prol da consecução desses objetivos, procedimentos avaliativos podem ser formulados pelo professor para aferir a assimilação dos referidos conteúdos. Em torno de cada palavra-chave selecionada para ser trabalhada na alfabetização podem ser organizadas atividades e sequências didáticas que configuram uma unidade de ensino a ser vencida pelo aluno. Tal elemento sequencial, presente em todas as cartilhas e métodos tradicionais de alfabetização, possibilita um acompanhamento da aprendizagem, inclusive por parte da família e do próprio aluno.

Fica patente, então, que o planejamento do alfabetizador pode se organizar a partir da objetivação dos conteúdos da linguagem escrita presentes em cada palavrachave, mobilizando os meios necessários para que essa objetivação ocorra da melhor forma possível na atividade do aluno. Do ponto de vista prático, é importante notar que delimitado um conjunto de palavras a ser trabalhado ao longo de um ano letivo, torna-se mais viável selecionar os elementos linguísticos, os textos e os exercícios de fixação a 
serem acionados em cada etapa do processo, oferecendo ao professor uma ferramenta de trabalho para alcançar seus objetivos. Isso contribui para reduzir os processos de alienação que esvaziam as atividades de planejamento (VOLPIN, 2016), e aponta para a necessidade de recuperar a autonomia e a capacidade teórico-crítica do professor que alfabetiza, valorizando o seu papel.

Essas propostas indicativas e as ideias desenvolvidas ao longo deste artigo objetivaram essencialmente apresentar um esboço introdutório sobre um caminho metodológico possível de ensino da escrita e da leitura numa perspectiva HistóricoCrítica. Portanto, são ideias ainda embrionárias a serem aprofundadas em estudos futuros. Esperamos que suscitem um debate profícuo que contribua para fazer avançar esses estudos.

\section{REFERÊNCIAS}

BAKHTIN, M.; VOLOCHINOV, V. N. Marxismo e filosofia da linguagem. São Paulo: Hucitec. 1986.

CAPOVIlla, A. G. S.; CAPOVILlA, F. C. C. Alfabetização: método fônico. São Paulo: Memnon, 2002.

COELHO, I. Pedagogia histórico-crítica e alfabetização: elementos para uma perspectiva histórico-crítica do ensino da leitura e da escrita. 2016. 116 f. Dissertação (Mestrado em Educação Escolar) - Universidade Estadual Paulista Júlio de Mesquita Filho, Araraquara, 2016.

DUARTE, N. Vigotski e o "aprender a aprender": crítica às apropriações neoliberais e pós-modernas da teoria vigotskiana. 2.ed. Campinas: Autores Associados, 2001.

FERREIRO, E. Reflexões sobre alfabetização. Tradução de H. Gonzales et al. São Paulo: Cortez, 1995.

GRAMSCI, A. Os intelectuais e a organização da cultura. 4.ed. Rio de Janeiro: Civilização Brasileira, 1982.

LURIA, A. R. Curso de psicologia geral. Rio de Janeiro: Civilização brasileira, 1979. $1 \mathrm{v}$.

LURIA, A. R. O desenvolvimento da escrita na criança. In: VIGOTSKI, L. S.; LURIA, A. R.; LEONTIEV, A. N. Linguagem, desenvolvimento e aprendizagem. São Paulo: Ícone, 2001. p.143-190.

LURIA, A. R. Pensamento e linguagem: as últimas conferências de Luria. Porto Alegre: Artes Médicas, 1986. 
MARTINS, L. M.; DANGIÓ, M. R. A concepção histórico-cultural de alfabetização. Revista Germinal: Marxismo e educação em debate, Salvador, v.7, n.1, p.210-220, jun. 2015 .

Disponível em: <http://www.portalseer.ufba.br/index.php/revistagerminal/article/view/13214/9533>. Acesso em: 12 jan. 2016.

MARTINS, L. M.; MARSIGLIA, A. C. G. As perspectivas construtivista e históricocrítica sobre o desenvolvimento da escrita. Campinas: Autores Associados, 2015.

MAZZEU, F. J. C. O uso de textos na alfabetização: contribuições para uma prática transformadora. In: PINHO, S. Z.; OLIVEIRA, J. B. B. (Org.). Núcleos de Ensino da Unesp [recurso eletrônico]: artigos dos projetos realizados em 2011. 1.ed. São Paulo: Cultura Acadêmica Editora, 2012. p.439-453. 2 v.

MENDONÇA, O. S.; MENDONÇA, O. C. Alfabetização: o método sociolinguístico: consciência social, silábica e alfabética em Paulo Freire. 3.ed. São Paulo: Cortez, 2009.

MEYER, K. Os gêneros textuais na alfabetização: uma análise da proposta apresentada no material "Ler e Escrever" da Secretaria Estadual de Educação do estado de São Paulo. 2016. 89 f. Dissertação (Mestrado em Educação Escolar) - Universidade Estadual Paulista Júlio de Mesquita Filho, Araraquara, 2016.

MORTATTI, M. R. L. Os sentidos da alfabetização. São Paulo: Ed. da UNESP, 2000.

SÃO PAULO. (Estado). Secretaria da Educação. Ler e escrever: Alfabetização: livro do aluno. Secretaria da Educação, Fundação para o Desenvolvimento da Educação. São Paulo: FDE, 2010.

SAVIANI, D. Educação: do senso comum à consciência filosófica. Campinas: Autores Associados, 1996.

SAVIANI, D. Escola e democracia. Campinas: Autores Associados, 2007.

SAVIANI, D. Pedagogia histórico-crítica: primeiras aproximações. Campinas: Autores Associados, 2013.

SOARES, M. Alfabetização: a questão dos métodos. Belo Horizonte: Editora Contexto. 2016.

SOARES, M. Letramento e alfabetização: as muitas facetas. Revista Brasileira de Educação, Rio de Janeiro, n.25, jan./abr. 2004.

VIEIRA PINTO, A. Ciência e existência: problemas filosóficos da pesquisa científica. 2.ed. Rio de Janeiro: Paz e Terra, 1979. (Pensamento crítico, 7).

VOLPIN, G. B. C. O significado e o sentido do planejamento no trabalho do professor: uma análise a partir da Teoria da Atividade. 2016. 151 f. Dissertação (Mestrado em Educação Escolar) - Universidade Estadual Paulista Júlio de Mesquita Filho, Araraquara, 2016. 
VYGOTSKY, L. S. Obras escogidas. Tomo III. Madri: Visor, 1995.

\section{Como referenciar este artigo}

COELHO, Izac Trindade; MAZZEU, Francisco José Carvalho. Notas introdutórias para um método histórico-crítico de alfabetização. Revista Ibero-Americana de Estudos em Educação, Araraquara, v.11, n. esp. 4, p. 2576-2593, 2016. Disponível em: <http://dx.doi.org/10.21723/riaee.v11.n.esp4.9210>. E-ISSN: 1982-5587.

Submetido em: setembro/2016

Aprovado em: novembro/2016 